\title{
El sufragio voluntario del artículo 15 de la Constitución Política de Chile
}

\author{
Diego Pardo Álvarez*
}

\begin{abstract}
RESUMEN
El artículo niega que el artículo 15 de la Constitución Política de Chile consagre el derecho a no asistir a sufragar. Lo que protege en cambio es la formación de la voluntad electoral del ciudadano. Bajo esta perspectiva se consideran varias disposiciones del sistema electoral chileno. Al no incluir este un derecho constitucional a la abstención electoral, cualquier restablecimiento legal de la obligación de sufragar no significaría afectación alguna del artículo 15 de la Constitución.
\end{abstract}

Sufragio voluntario - derechos políticos - Constitución chilena

\section{Voluntary voting in the article 15 of the Chilean Constitution}

\begin{abstract}
The paper denies that art. 15 of the chilean Constitution establishes a right not to vote. What is instead protectected by this article is the citizen's electoral decision-making process. Under this perspective are considered several statements from chilean electoral system. Since a constitutional right not to vote is not included in it, any new legal statement that establishes compulsory voting would involve no transgression to art. 15 of the Constitution.
\end{abstract}

Voluntary voting - political rights - Chilean Constitution

* Abogado, Becario de la Fundación Konrad Adenauer para la realización de estudios de doctorado en la Georg-August-Universität, Gotinga, Alemania. Agradezco a Javier Contesse Singh, Valeria Lübbert Álvarez y Juan Pablo Mañalich Raffo por los comentarios hechos a una versión preliminar de este trabajo. Correo electrónico: diegopa@gmail.com

Artículo recibido el 30 de marzo de 2013 y aceptado para su publicación por el Comité Editorial el 28 de octubre de 2013. 
$\mathrm{N}$ o se desarrollará en este trabajo una justificación del sufragio obligatorio. El tema ya ha sido tratado en la atractiva y breve disputa teórica que se presentó en la doctrina chilena en la antesala de la modificación de los artículos 15 y 18 de la Constitución. ${ }^{1}$ La disputa resultó atractiva en tanto bajo su alero se desarrollaron posiciones filosóficas y políticas complejas y radicales. Ella fue no obstante breve, pues la modificación constitucional, aparentemente, declaró como triunfadores a los defensores del sufragio voluntario.

El objetivo de este trabajo, en cambio, es presentar una interpretación del nuevo artículo 15 de la Constitución. Defenderé (II) que el actual artículo 15 no consagra lo que a fuerza de repetición se ha entendido como sufragio voluntario, i.e. el derecho del ciudadano de no asistir a sufragar. El sistema constitucional chileno actual, más bien, establece las condiciones estructurales para entender al sufragio como una manifestación de voluntad del ciudadano (III). Ello no necesariamente implica el derecho de no asistir a sufragar.

Por ello, al concluir, afirmaré que la actual regulación constitucional no impide que mediante la legislación pueda establecerse cualquier tipo de incentivo para obtener mayor participación electoral. Ello incluye ciertamente la posibilidad de multar a quien se abstuviese de sufragar.

\section{I.}

\section{Derecho y privilegio}

Buena parte de la discusión sobre la obligatoriedad del sufragio se basa en un malentendido de lógica deóntica. En el medio jurídico y político chileno se ha afirmado que todo derecho, y por ende también el derecho de sufragio, sería incompatible con la obligación (de sufragio), i.e. que todo derecho a $\varphi$ sería incompatible con la obligación a $\varphi^{2}$. Luego, si existe el derecho de sufragio, entonces conceptualmente no podría existir

${ }^{1}$ Véase Sierra, L., "El voto como derecho: una cuestión de principios", en PNUD, Modernización del régimen electoral chileno, Santiago, 2007; Chuaqui, T., "Participación electoral obligatoria: una defensa", en PNUD, Modernización del régimen electoral chileno, Santiago, 2007; Marshall, P., "El derecho y la obligación de votar”, en Revista de Derecho, Universidad Austral de Chile, vol. XXII (1), 2009; Zúñiga, P. "Derecho de sufragio y obligatoriedad", en Hemiciclo. Revista de Estudios Parlamentarios, Academia Parlamentaria, vol. 1 (1), 2009.

2 Sierra, L. (Op. cit., p. 157) afirma que "en materias de régimen electoral, la pregunta que interroga por el carácter normativo del voto, es decir, la pregunta acerca si se trata de un derecho o un deber, es quizá la que está más intensamente asociada a cuestiones de principio..." (énfasis añadido); Chauqui, T. (Op. cit., p. 195): "la participación electoral debería ser considerada como un deber y no como un derecho" (énfasis añadido). Álvaro Fischer (El Mercurio, 28 de diciembre de 2011) afirma que sostener que el voto es a la vez un derecho y un deber es "lógicamente inconsistente o analíticamente imposible.", pues "las personas o tienen 'derecho' a voto, o tienen 'deber' de votar, pero no pueden tener ambos a la vez” (énfasis añadido). Asimismo la Ley N 20.337 lleva por título "Reforma constitucional que modifica los artículos 15 y 18 de la Carta Fundamental, con el objeto de consagrar el sufragio como un derecho de los ciudadanos y de su inscripción 
la obligación de sufragar. La profundidad de este malentendido exige una disolución desde el punto de vista estrictamente analítico. Ella ya ha sido proveída por Pablo Marshall, por lo que se reproducirá su argumento con el fin de clarificar los conceptos que se utilizarán en el resto de la exposición.

Marshall demuestra que no existe incompatibilidad alguna entre derecho y obligación tomando como apoyo una distinción delineada ya en 1919 por W.N. Hohfeld ${ }^{3}$. Considérese el siguiente cuadro:

\begin{tabular}{l|l}
\hline Posición jurídica & Posición correlativa \\
\hline derecho & deber \\
\hline privilegio & no derecho \\
\hline
\end{tabular}

Hohfeld afirma que un derecho es aquella posición jurídica que tiene como posición correlativa un deber ajeno ${ }^{4}$. Imagínese que la persona $\mathrm{X}$ cuenta con el derecho de impedir a $\mathrm{Y}$ el ingreso a un determinado inmueble. La posición correlativa de este derecho es el deber de $\mathrm{Y}$, quien frente a $\mathrm{X}$ debe no ingresar a dicha propiedad. Puede observarse que el que $\mathrm{X}$ esté o no obligado con $\mathrm{Y}$, en cambio, es una cuestión completamente independiente a los derechos de X frente a Y. Por ello, continuando con el ejemplo dado por Hohfeld, X podría estar obligado con Y a ingresar a la propiedad ${ }^{5}$ : el correlativo al derecho propio es la obligación ajena; la existencia de una obligación propia, en cambio, no tiene una relación conceptual o necesaria con el propio derecho.

Hohfeld pretende diferenciar la noción de derecho de la de privilegio. La posición correlativa de un privilegio no es un deber ajeno, sino el no derecho ajeno. El que X cuente con el privilegio de ingresar a un determinado inmueble significa que no debe omitir ingresar a la propiedad. Bajo una reformulación analítica, el correlativo de este privilegio es el "no derecho" de Y para exigir a X que omita ingresar ${ }^{6}$. Es decir, porque $\mathrm{X}$ tiene el privilegio para ingresar a la propiedad, $\mathrm{Y}$ no tiene derecho frente a $\mathrm{X}$ para exigirle que omita ingresar.

automática en los Registros Electorales” (énfasis añadido). También lo entendió así Enna von Baer y Hernán Larraín Matte (véase el Primer Informe de la Comisión de Constitución, Legislación, Justicia y Reglamento recaído sobre el proyecto de reforma constitucional, Boletín $\mathrm{N}^{\circ}$ 3544-07). Invitado fue también el entonces presidente de la Fundación Futuro, Sebastián Piñera, quien centró su reflexión "en si el voto es un derecho o una obligación, pues (...) estas condiciones no pueden compatibilizarse” (énfasis añadido).

${ }^{3}$ Marshall, P., Op. cit., pp. 79 y ss. Hohfeld, W.N., Fundamental legal conceptions as applied in judicial reasoning and other legal essays, Yale University Press, New Haven, 1919, pp. 35 y ss.

${ }^{4}$ Hohfeld, W.N., Ibid., p. 38.

${ }^{5}$ Hohfeld imagina, por ejemplo, que quien goza del privilegio a ingresar a determinado inmueble puede estar a la vez obligado por contrato a ingresar.

${ }^{6}$ De la existencia de un "no derecho" no puede concluirse, empero, la existencia de una obligación de los terceros: "Los únicos correlativos [correlative] implicados lógicamente por los privilegios o libertades en cuestión son los 'no derechos' de los terceros. Sería entonces un non sequitur concluir de la mera existencia de tales libertades que los terceros están sometidos a un deber de no interferir". Véase Hohfeld, W.N. Op. cit., p. 43. 
Como puede apreciarse, el privilegio es solo analíticamente incompatible con el deber propio de contenido contrario, i.e., quien cuenta con el privilegio a $\varphi$ no puede estar obligado a no $\varphi$. Es una cuestión independiente que quien cuente con un privilegio (e.gr. a ingresar a determinado inmueble) pueda estar a la vez obligado (e.gr. a ingresar al mismo inmueble). La posibilidad lógica de esta alternativa es manifiesta.

Para Marshall esta diferenciación conceptual tendría un sentido material evidente: el derecho constituiría para el sujeto una posición ofensiva, que consistiría en exigir a otro una ejecución u omisión determinados. El privilegio, en cambio, sería una posición meramente defensiva: impediría que otros afecten la ejecución u omisión privilegiada ${ }^{7}$. No es necesario comentar esta conclusión acá ${ }^{8}$. Basta con aclarar que, traducido al lenguaje de la regulación del sufragio, el derecho de sufragio implica que el Estado está obligado a la realización de elecciones en la forma prescrita por la Constitución. El privilegio de sufragar, en cambio, implica que el Estado no tiene derecho a impedir su ejercicio.

\section{Privilegio y libertad}

Tampoco ha sido utilizada con toda claridad la noción de libertad frente a la regulación del sufragio. Hohfeld considera, equívocamente, que los términos privilegio y libertad son equivalentes ${ }^{9}$. Acaso no de forma consciente, el trabajo de Marshall mantiene dicha equiparación, pero bajo un diferente sentido:

Como la posición jurídica opuesta al deber se ubica la libertad (o privilegio en términos de Hohfeld). La libertad es aquella posición en la que se niega la existencia de un deber. Un sujeto es libre cuando no está obligado a realizar ( 0 abstenerse de realizar) una conducta determinada ${ }^{10}$.

Aparentemente Marshall concibe a la libertad (o privilegio) como equivalente a lo que Von Wright denominó indiferencia. El rasgo caracterísco de la indiferencia es su doble contenido: el agente cuenta con un privilegio para ejecutar una acción determinada y

${ }^{7}$ Marshall, P. Op. cit., pp. 83-4.

${ }^{8}$ Marshall espera demasiado del privilegio. Ello puede observarse cuando se atiende a la formulación del problema desarrollada por G.H. von Wright. El privilegio (tolerancia para Von Wright) constituye una posición defensiva solo en la medida en que significa que la intervención ajena no es fundada ni sustentada por un derecho, i.e., que hay un no derecho. Es ese preciso sentido un privilegio es una tolerancia. Marshall parece entender por posición defensiva, en cambio, el que la acción privilegiada pueda gozar de protección jurídica. Esta posibilidad de defensa jurídica implicaría eo ipso, en cambio, que el privilegio es ya un derecho. Por ello, la posición defensiva que otorga un privilegio es una posición precaria, basada en una simple negación (de un derecho ajeno): la autoridad normativa puede decidir en cualquier momento revertir su tolerancia inicial. Marshall parece hacer eco de otra sugerencia de Von Wright (citando a Kelsen): "Puede sugerirse que es inherente a la naturaleza del permiso el implicar derechos y/o acciones. (...) Puede también sugerirse que el único sentido en que las leyes del Estado son permisivas es prohibiendo interferencias a la conducta de los agentes en determinados respectos". Ambas sugerencias, desde luego, no son consecuencias necesarias (véase Von Wright, G.H., Norm and Action. A logical enquiry, Routledge und Kegan Paul, Londres, 1963, p. 90).

${ }^{9}$ Véase Hohfeld, W.N. Op. cit., pp. 42-3.

${ }^{10}$ Marshall, P. Op. cit., p. 81. Énfasis añadido. 
con un privilegio para omitir la misma acción determinada ${ }^{11}$. En rigor, sin embargo, libertad (o privilegio) en Hohfeld no equivalen a indiferencia ${ }^{12}$. Pues como ya se afirmó, es perfectamente posible que el agente tenga el privilegio a ejecutar $\varphi$ y la obligación a ejecutar $\varphi$, es decir, no tenga el privilegio a omitir $\varphi^{13}$.

Por ello la indiferencia, i.e. la conjunción entre el privilegio a ejecutar $\varphi$ y el privilegio a omitir $\varphi$, se denominará libertad (siguiendo a Marshall) ${ }^{14}$. Se mantendrá en cambio la noción de privilegio para la comprensión hohfeldiana estricta. Bajo esta diferenciación, un privilegio es compatible con la propia obligación; una libertad, en cambio, no. Luego, la tesis presentada al inicio de este trabajo es incorrecta: el derecho a sufragio es plenamente compatible con la obligatoriedad del sufragio. Lo que resulta incompatible es la obligatoriedad del sufragio y la libertad de sufragio. El reconocimiento de esta última noción -la libertad de sufragio- en la Constitución es, como se expondrá (infra II), problemático.

\section{Derecho y libertad en la Constitución}

En la Constitución se dejan reconocer tanto derechos como libertades, en ciertas disposiciones de forma expresa. Es el caso del derecho a la vida ${ }^{15}$, la libertad ambulatoria, de expresión, de conciencia y de trabajo. Más recurrentes y complejos son los casos en que dicho reconocimiento expreso se ve modificado por una declaración constitucional complementaria, que establece el cumplimiento obligatorio de un derecho ${ }^{16}$ (descartandose entonces que sea una libertad); o que muta, a la inversa, un derecho en una libertad $^{17}$. Casos especiales de esta última constelación son aquellos en donde se reconoce

${ }^{11}$ Fackeldey, H.G., Norm und Begründung. Zur Logik normative Argumentierens, Peter Lang, Berna, 1992, p. 34.

${ }^{12}$ La diferencia conceptual entre Marshall y Hohfeld yace probablemente en la equívoca formulación de Hohfeld al discutir la relación entre privilegio y libertad. Contrástese lo afirmado por Hohfeld (Op. cit., pp. 39 y 44). Aquí puede apreciarse que para Hohfeld "privilegio" denota la negación de un deber, pero no la negación de todo deber. El privilegio a $\varphi$ significa la negación del deber a no $\varphi$. El deber a $\varphi$, sin embargo, es una cuestión ulterior.

13 VéaseVon Wright, G.H.: “Deontic Logic”, en Mind, Vol. 60 (237), 1951, p. 4.

${ }^{14}$ Con ello se da pie a la intuición, sostenida entre otros por Austin y Bentham, de que el concepto constitucional de libertad correspondería, prima facie, al de indiferencia. Por todos véase Bragvyova, A.: "Freedom and permission", en Archiv für Rechts- und Sozialphilosophie, Vol. 91, 2005, pp. 386-7.

15 Aunque presenta algunas complejidades, es suficiente afirmar que desde el punto de vista del artículo $19 \mathrm{~N}^{\mathrm{o}} 1$ el derecho a la vida se reconoce solamente como derecho a vivir, no como derecho a morir. El reconocimiento de un derecho a morir, i.e., de una permisión del suicidio, es una cuestión sobre la que el artículo $19 \mathrm{~N}^{\circ} 1$ nada dice.

${ }^{16}$ Por ejemplo, el artículo 19 No 10 de la Constitución protege el derecho a la educación, no la libertad de educación, pues "la educación básica y media son obligatorias". También reconoce el derecho preferente y el deber de los padres de educar a sus hijos. Es decir, los padres tienen un derecho y un deber.

${ }^{17}$ El derecho de asociación del artículo $19 \mathrm{~N}^{\circ} 15$ especifica, en su tercer inciso, que nadie puede ser obligado a pertenecer a una asociación. Luego, existe una derecho a pertenecer a una asociación y un derecho a no pertenecer a alguna. Puede afirmarse, en consecuencia, que existe una libertad de asociación protegida constitucionalmente. 
el derecho a ejecutar una acción en la Constitución y el derecho a omitir dicha acción en una disposición de menor jerarquía ${ }^{18}$. En estos casos no es completamente exacto hablar de una libertad constitucional, pues solo uno de los derechos tiene esta jerarquía. Lo que es necesario reconocer, en cualquier caso de libertad, es que ella está compuesta de un doble contenido normativo (i.e., dos privilegios): uno referido a la ejecución de una acción determinada, y otro referido a la omisión de dicha determinada acción.

II.

El derecho de sufragio encuentra reconocimiento explícito en el artículo 13 de la Constitución:

"La calidad de ciudadano otorga los derechos de sufragio, de optar a cargos de elección popular y los demás que la Constitución o la ley confieran”.

Antes de la reforma constitucional este derecho coexistía con la obligación de sufragio del antiguo artículo 15. Producto de la aprobación de la Ley No 20.337 de reforma constitucional, el primer inciso del artículo 15 fue modificado como sigue:

\begin{tabular}{l|l}
\hline Antes de la reforma & Después de la reforma \\
\hline $\begin{array}{l}\text { En las votaciones populares, el sufragio } \\
\text { será personal, igualitario y secreto. Para } \\
\text { los ciudadanos será, además, obligatorio }\end{array}$ & $\begin{array}{l}\text { En las votaciones populares, el sufragio } \\
\text { será personal, igualitario, secreto y } \\
\text { voluntario }\end{array}$ \\
\hline
\end{tabular}

Con anterioridad no podía reconocerse una libertad constitucional al sufragio. Para afirmar que con posterioridad a la reforma sí existiría dicha libertad, tendría que comprobarse que la Constitución incluye, además del derecho a sufragio del artículo 13, un derecho a la abstención ${ }^{19}$.

Aquí es necesario hacer dos precisiones conceptuales:

${ }^{18}$ El artículo $19 \mathrm{~N}^{0} 7$ lit. f reconoce el derecho del imputado a guardar silencio. Desde el punto de vista constitucional no hay impedimento alguno para que el imputado sea también obligado a guardar silencio. El artículo 93 lit. g, el 91 inc. $2^{\circ}$ y sobre todo el artículo 98 del Código Procesal Penal, en cambio, hablan a favor de reconocer que el imputado goza de una libertad: puede tanto hablar como guardar silencio. Así, su derecho a guardar silencio goza de protección constitucional; su derecho a prestar declaración, en cambio, no: este último goza solo de protección legal. Ello es importante frente a los requisitos procedimentales de su modificación, mucho más estrictos en el caso de una modificación constitucional que en el caso de una modificación legal.

${ }^{19}$ Se utilizará en lo que sigue la noción de derecho frente a la de privilegio, pues es difícil concebir una norma constitucional que solo otorgue un privilegio, es decir, que no provoque que al menos una agencia del Estado resulte obligada. Al respecto véase lo afirmado supra, en nota 8. 
(1) En Norm and Action, Von Wright distingue entre permiso en sentido débil y permiso en sentido fuerte. El núcleo de la distinción radica en si la permisión de determinada acción se encuentra o no sujeta a tratamiento normativo por parte de la autoridad ${ }^{20}$.

Esta distinción ha dado pie a un intenso debate y múltiples equívocos. Resulta significativa aquí solo en la medida en que un permiso en sentido fuerte conlleva el efecto de norma precludendi, i.e. imposibilita la promulgación de disposiciones obligatorias o prohibitivas de menor jerarquía ${ }^{21}$. Un permiso en sentido débil (en la Constitución), en cambio, interesa en tanto implica la detección de espacios carentes de regulación (constitucional), descartándose con ello alguna limitación al ámbito de competencia de menor jerarquía.

(2) Puede distinguirse entre un concepto débil y uno fuerte de abstención: según el sentido débil, el elector puede abstenerse de marcar una preferencia de entre las incluidas en la papeleta electoral; conforme al sentido fuerte, el elector puede (al menos) abstenerse de depositar la papeleta electoral ${ }^{22}$. Si la modificación constitucional del artículo 15 se hubiese limitado a consagrar solo un permiso para abstenerse de marcar una preferencia, entonces sería una reforma espuria. Pues la abstención en sentido débil es fácilmente reconocible en la Constitución, ya sea mediante una apelación a la libertad de expresión, al secreto del sufragio o a la posibilidad de dejar en blanco la papeleta electoral (Art. 26 inc. $3^{\circ}$ de la Constitución). Por ello solo la abstención en sentido fuerte es relevante para este trabajo.

Se entenderá entonces por derecho a la abstención, el permiso en sentido fuerte para una abstención en su sentido fuerte. Expondré en este apartado las dificultades a que se vería sometido el intento de justificar la existencia de dicho derecho a la abstención en la Constitución. En el siguiente apartado (infra III) sostendré una tesis interpretativa que, creo, no se ve sometida a los mismos reparos.

\section{El sufragio "voluntario"}

El principal punto de apoyo que se aduce para considerar que existiría un derecho a la abstención en la Constitución es el nuevo artículo 15, que establece que "el sufragio será personal, igualitario, secreto y voluntario”. La pregunta central que presenta la modificación es si con ella se incluye en la Constitución un derecho a la abstención.

${ }^{20}$ Alchourrón, C. y Bulygin, E., Normative Systems, Springer, Nueva York, 1971, p. 124.

${ }^{21}$ Iturralde, V., "Consideración crítica del principio de permisión según el cual 'lo no prohibido está permitido”, en Anuario de Filosofía del Derecho, vol. 15, 1998, p. 195.

22 Esta es una reformulación de la distinción entre "obligatoriedad de la participación electoral" y "obligatoriedad del voto” sugerida por Chuaqui, T., Op. cit., p. 196. También, mas no necesariamente, podría el elector abstenerse de asistir al local de votación y de firmar los registros electorales correspondientes. 
El punto clave del argumento a favor de una respuesta positiva radica en la introducción de la palabra voluntario en el artículo 15. Para justificar que ello implicaría un derecho a la abstención habría dos razones, a mi juicio insuficientes: su tenor literal y la intención legislativa.

\subsection{El tenor literal}

La discusión sobre el estatus normativo del sufragio ha estado permeada por dos errores conceptuales: el primero es la supuesta incompatibilidad entre derecho y obligación (revisada en supra I); el segundo es la supuesta incompatibilidad entre los términos voluntario y obligatorio ${ }^{23}$. Esta confusión podría servir como apoyo para la justificación de un derecho a la abstención. Sufragio voluntario, siguiendo esta línea argumentativa, sería aquel que nace de la voluntad espontánea del elector, lo que sería incompatible con cualquier obligación o deber. Luego, voluntario significaría que el legislador no puede establecer una obligación al sufragio.

Lo correcto de esta tesis es que sufragio voluntario significa que el legislador debe establecer las condiciones para que el sufragar admita ser descrito como una acción voluntaria. Este entendimiento se desarrollará en infra III. Esto no significa, en cambio, que el legislador esté impedido de reestablecer la obligación de sufragio. Pues la palabra voluntario en el artículo 15 no justifica un derecho a la abstención oponible al legislador, al menos por dos razones.

La primera razón es gramatical. Voluntario es un adjetivo que se predica del "sufragio", en "las elecciones populares". Según el artículo 13, sufragio es un derecho del ciudadano. De esta formulación no puede deducirse la existencia de un derecho a la abstención (supra, I). Luego, el adjetivo voluntario, en principio, no se predica de la abstención: el artículo 15 (solo) califica como voluntario al sufragio, no a la abstención. Para que el adjetivo voluntario también fuera predicado de la abstención, tendría que darse por probado precisamente lo que pretende defenderse: que existe un derecho a la abstención en la Constitución.

La segunda razón es una de teoría de la acción. El argumento a favor de la supuesta implicación entre sufragio voluntario y abstención evoca cierta comprensión del principio de las posibilidades alternativas ${ }^{24}$. Pues si la Constitución ordena que el sufragio debe entenderse como una acción voluntaria, entonces ello implicaría que quien va a sufragar debiera tener la posibilidad de no hacerlo. Así, sufragio voluntario implicaría que al elector le asiste el derecho de abstención, pues de otra forma su sufragio no podría entenderse como voluntario según la Constitución.

${ }^{23}$ Chauqui, T., Op. cit., p. 183; Sierra, L. Op. cit., p. 157 y ss. Ellos no se refieren a la formulación del artículo 15, pues para ese entonces no se encontraba aún promulgada la reforma constitucional.

24 "Este principio establece que una persona es moralemente responsable por lo que ha hecho solo si podría haberlo hecho de otra manera". Frankfurt, H., The importance of what we care about, Cambridge University Press, Nueva York, 1998, p. 1. Para una crítica adicional, Davidson, D., "Freedom to act", en, del mismo, Essays on actions and events, Clarendon Press, Oxford, 1980, pp. 74-5. 
Pero eso no se sigue. Una acción voluntaria no es definible como aquella acción que puede evitarse: ella puede ser de hecho inevitable para el agente ${ }^{25}$. A fortiori, una acción voluntaria también puede ser obligatoria. Es nornal que se satisfagan voluntariamente obligaciones, i.e., se ejecuten voluntariamente acciones aun cuando confluye la obligación de ejecutarla. Piénsese en las obligaciones que se satisfacen en el contexto familiar, como la obligación de alimentos o de fidelidad, por ejemplo. O en el cumplimiento voluntario de un contrato, que es una "ley para las partes". Por ello, si no se reconociera un derecho de abstención, no se afectaría con ello el carácter voluntario del sufragio ${ }^{26}$.

Por estas dos razones, el adjetivo voluntario no tiene el rendimiento suficiente como para consagrar un derecho a la abstención. Se postulará que el sentido de la calificante en realidad es otro: el que una acción sea voluntaria radica en que el agente no padezca de algún defecto deliberativo ${ }^{27}$. Qué significa defecto deliberativo con precisión debe determinarse en concreto: se hará una formulación tentativa en la tercera parte de este trabajo. El objetivo de esta sección se limita a defender la idea de que voluntario no necesariamente significa la posibilidad de abstenerse de sufragar: el sufragio puede ser voluntario aunque el elector esté obligado a depositar la papeleta electoral (véase al respecto infra III, 2.4).

\subsection{La intención legislativa}

Una segunda razón para considerar que la modificación del artículo 15 consagra un derecho a la abstención sería proveída por la propia discusión que tuvo lugar en el Congreso. Tanto en sala como en comisiones se operó bajo el presupuesto de que la modificación del artículo 15 respondía al deseo de consagrar un derecho de abstención a favor del ciudadano, permitiéndose con ello que quien no quisiera sufragar simplemente se ausentara del acto electoral.

La tesis de la intención legislativa como fundamento de una interpretación se deja reconstruir como un capítulo de la antigua querella entre originalismo y objetivismo

${ }^{25}$ Los casos de sobredeterminación causal están en la base de la crítica de Frankfurt. Ellos son, básicamente, aquellos casos en los que se está determinado causalmente a ejecutar una acción, la que no obstante se ejecuta voluntariamente. Véase Frankfurt, H., Op. cit., pp. 8 y ss.

26 Detrás de esto yace una razón gramatical. Pues adviértase el sentido de la oración "el ciudadano emitió un sufragio voluntario". Aquí lo "voluntario" es el sufragio, no la emisión del ciudadano. La frase "el ciudadano obligatoriamente emitió un sufragio voluntario" tendría tanto sentido como afirmar "el ciudadano manualmente emitió un sufragio electrónico" o "el ciudadano pública y abiertamente emitió un sufragio secreto”. Los primeros elementos son expresiones adverbiales que califican la acción del agente; los segundos son adjetivos que califican al sufragio como institución. El art. 15, así, califica a la institución del sufragio, no a la acción del ciudadano al sufragar. La palabra "voluntad" no necesariamente tiene el mismo sentido como adjetivo y como adverbio. (Los ejemplos son una reformulación de la discusión iniciada por Austin, J.L., “A plea for excuses”, en, del mismo: Philosophical Papers (segunda edición), Oxford University Press, Oxford, 1970. pp. 180-204; y continuada por Vendler, Z., “Agency and Causation”, en Midwest Studies in Philosophy IX, 1984, pp. 376-8).

27 Williams, B., "How free does the will need to be?" en, del mismo, Making sense of Humanity, Cambridge University Press, Cambridge, 1995, p. 25. 
frente a la práctica constitucional estadounidense ${ }^{28}$. Por supuesto, no es posible ni necesario dar cuenta de ella en la presente exposición. Basta con afirmar que es muy difícil reconocer en un cuerpo colegiado una opinión legislativa inequívoca, más allá de lo expresado en el propio texto promulgado ${ }^{29}$. Aun cuando esta pudiere reconocerse con claridad, no hay razón alguna para sostener una interpretación solo a base de la opinión de quienes redactaron una disposición ${ }^{30}$. La Constitución, como cualquier otro texto autoritativo, es un compendio de disposiciones, no de intenciones ${ }^{31}$. Al interpretarse en cambio una disposición constitucional exclusivamente basada en la intención al momento de su discusión, se pone en tela de juicio el carácter normativo y positivo de las disposiciones constitucionales ${ }^{32}$.

\subsection{La historia fidedigna}

La Ley $N^{\circ} 20.337$ efectúa tres modificaciones a la Constitución: modifica el artículo 15 , el artículo 18 y agrega la disposición transitoria $\mathrm{N}^{\circ} 23$. En virtud de esta última, las modificaciones de los artículos 15 y 18 entrarían en vigencia una vez dictada la ley orgánica

${ }^{28}$ Para una descripción sucinta, véase Heun, W., "Originalism als Interpretationsmethode im US.-amerikanischen Verfassungsrecht”, en Rainer Wahl (ed.), Verfassunsänderung, Verfassungswandel, Verfassungsinterpretation, Duncker \& Humblot, Berlin, 2008.

29 "El conocimiento del fundamento de una ley puede ser más o menos seguro. La mayor seguridad se obtiene mediante la expresión de su fundamento en la propia ley". Savigny, F. C. Von, System des heutigen Römischen Rechts (Libro I), Velt und Comp., Berlín, 1848, p. 218.

${ }^{30}$ La vinculación entre intención legislativa y la "historia fidedigna de su establecimiento" del artículo 19 inc. $2^{\circ}$ del Código Civil no es sostenible. Establecimiento no significa tramitación, y la historia fidedigna no se concreta en las opiniones sostenidas dentro del proceso de creación de una norma. La historia fidedigna se refiere, en cambio, a la evolución de la disposición dentro del sistema jurídico. Esto ya se afirma en la “interpretación de las leyes en su estado saludable" de Savigny (Op. cit., p. 214): "El elemento histórico tiene por objeto el estado actual de las relaciones jurídicas, dispuesto a través de las disposiciones jurídicas [Rechtsregeln] al momento de ser promulgada la ley".

${ }^{31}$ Puede sostenerse, entonces, una negativa opinión de la capacidad de los legisladores para plasmar su intención en un cuerpo legal. Esto es manifiesto cuando se analizan las alternativas con que se contaba para dictar lo que aparentemente se pretendía dictar: El art. 38 inc. $1^{\circ}$ de la Ley Fundamental alemana establece que "Los Diputados del Parlamento Alemán serán elegidos en elección general, directa, libre, igualitaria y secreta"; el artículo 68 de la Constitución Española establece que "El Congreso se compone de un mínimo de 300 y un máximo de 400 Diputados, elegidos por sufragio universal, libre, igual, directo y secreto, en los términos que establezca la ley". En ambos casos se usa la expresión "libre", que podría haber dado pie a menos equívocos. Incluyo estos ejemplos no de forma azarosa, sino porque ambos fueron citados como sistemas de "voto voluntario" por el entonces Ministro Secretario General de la Presidencia, Sr. Viera-Gallo (en la discusión en sala de la Ley $\mathrm{N}^{\circ} 20.337$ en el Senado, legislatura 356, 1 Sesión del 11 de marzo de 2008). A pesar de haber tenido estos modelos a la vista, el constituyente optó en definitiva por la fórmula propuesta por el senador Espina, sin mayor expresión de fundamento sistemático. Véase el segundo informe de la Comisión de Constitución, Legislación y Justicia del Senado, cuenta en sesión 78, legislatura 356, del 5 de diciembre de 2008.

32 Ello es lo que está detrás de la crítica a la tópica como teoría de la interpretación constitucional. Al respecto, Böckenförde, E.- W., "Die Methoden der Verfassungsinterpretation - Bestandaufnahme und Kritik”, en, del mismo, Wissenschaft, Politik, Verfassungsgericht, Suhkamp, Berlin, 2011, pp. 127-36. 
constitucional a la que se refiere el inc. $2^{\circ}$ del artículo 18 . Ello tuvo lugar mediante la dictación de la Ley $\mathrm{N}^{\circ}$ 20.568, el 31 de enero de 2012. Una de los artículos de dicha ley reemplaza el antiguo artículo 139 de la ley de votaciones populares y escrutinios, que sancionaba al ciudadano que no votare con una multa a beneficio municipal de media a tres unidades tributarias mensuales.

El artículo 7 de la Constitución de 1925 consagraba tanto el derecho a sufragio como su principal rasgo característico: el secreto ${ }^{33}$. La norma pertenecía al capítulo de "Nacionalidad y Ciudadanía”. La obligación de sufragio, en cambio, encontraba reconocimiento simplemente legal ${ }^{34}$. Esta estructura se mantuvo tanto en la Constitución de 1980 como en su formulación de 1989, consagrándose el derecho a sufragio en el artículo 13 y las características del sufragio en el artículo 15; ambos también pertenecientes al capítulo de "Nacionalidad y Ciudadanía", no al de "Derechos y Deberes Constitucionales" 35 .

La Constitución de 1980 tenía, sin embargo, una peculiaridad respecto de la de 1925: la obligación de sufragar. Ella representaba una peculiaridad sistemática, pues ahora la obligación era objeto de una disposición de rango constitucional y porque, a diferencia del resto de las características del artículo 15, la obligación se dirigía expresamente a "los ciudadanos" 36 . Con su derogación, mediante la Ley $\mathrm{N}^{\circ} 20.337$, se eliminó la única referencia a los ciudadanos en el artículo 15: actualmente, todas las características consagradas en él se refieren al "sufragio" en las "votaciones populares".

Según su historia, puede observarse que la reforma constitucional y legal tuvo por objeto derogar la obligación de sufragio en ambos niveles. Históricamente, en cambio, no puede reconocerse una evolución tendiente a reconocer un derecho constitucional a la abstención del ciudadano. Ello porque, como ya se expresó, se eliminó la única referencia explícita al ciudadano en el artículo 15. En segundo lugar, porque no se efectuó reforma alguna al capítulo de "derechos y deberes ciudadanos". En tercer lugar porque, desde la lectura conjunta de los artículos $15,18,63 \mathrm{~N}^{\text {os }} 1$ y 20 y de la disposición transitoria $\mathrm{N}^{\circ} 23$, puede deducirse que la Constitución reconoce competencia al legislador para regular y concretar la institución del sufragio: ello es lo que subyace al hecho de que la reforma constitucional rigiera solo una vez promulgada la ley orgánica constitucional a que se refiere el artículo 18 de la Constitución. Desde el punto de vista constitucional, la construcción del sistema de votaciones populares se realiza legislator interposita. Una interpretación que limite la competencia legislativa requiere de argumentos adicionales.

33 "Son ciudadanos con derecho a sufragio los chilenos que hayan cumplido 18 años de edad y estén inscritos en los registros electorales. (...)”. " [inc.. $3^{\circ}$ ] En las votaciones populares el sufragio será siempre secreto".

${ }^{34}$ Véase los artículos 62 y 156 de la Ley No 14.852, publicada en 1962, que fijaba el texto definitivo de la ley general de elecciones.

35 Todas las características iniciales del sufragio fueron objeto de discusión diferenciada en la comisión Ortúzar. Véase las actas de las sesiones $\mathrm{N}^{\circ} 73$ del 26 de septiembre de 1974 y $\mathrm{N}^{\circ} 74$ del 30 de septiembre del mismo año.

${ }^{36}$ Reconoce Evans en la sesión N 75 del 3 de octubre de 1974 que la obligación de sufragar, a diferencia del carácter personal, igualitario y secreto, "es una característica específica para los ciudadanos". 


\subsection{Consideraciones sistemáticas}

El sufragio es una institución formalizada. En ciertos casos, y dependiendo de su concreción legal, sus características pueden traducirse en un derecho, en un permiso o incluso en una obligación para el ciudadano. Ello depende de la configuración concreta al momento de su establecimiento en la ley ${ }^{37}$. El secreto del sufragio, por ejemplo, se desempeña como un derecho a favor del ciudadano y como un deber para él mismo ${ }^{38}$. Esto es natural, pues el secreto busca evitar el cohecho. De la misma forma, el sufragio "personal" e "igualitario" pretende evitar el cohecho y el voto censitario, es decir, son en determinados contextos un derecho y en otros un deber para quien vota ${ }^{39}$. Si la palabra voluntario consagrase directamente un derecho a la abstención para el ciudadano, ello representaría una anomalía en función de la propia sistemática interna del artículo 15. Igual que las otras características, voluntario se refiere al sufragio. Su relación con el ciudadano requiere de la mediación de la ley.

Como ya se ha repetido, el derecho a sufragio se encuentra consagrado en el artículo 13 de la Constitución, mientras que los derechos y deberes constitucionales están en el artículo 19. Ambas disposiciones se ubican en capítulos distintos de la Constitución. A su vez el artículo 15 pertenece al capítulo de "nacionalidad y ciudadanía", igual que el artículo 13. Desde el punto de vista de la sistemática constitucional, se requieren argumentos adicionales para considerar que el artículo 15 establece un derecho constitucional a la abstención, siendo que no se ubica en el capítulo constitucional destinado al efecto. Desde luego no hace falta ir muy lejos para reconocer derechos en otros capítulos de la Constitución: el propio derecho de sufragio es uno de ellos. En este caso, sin embargo, hay un reconocimiento expreso. Y como ya se afirmó, desde el derecho a sufragio no puede deducirse un derecho a la abstención. La calificación como voluntario no aporta elementos adicionales a este respecto.

III.

El onus probandi de la justificación de un derecho de abstención corresponde a quien quiera demostrarlo. Hasta ahora la exposición podría entenderse como una enumeración de los desafíos a los que dicho intento se vería enfrentado. Según lo expresado, dicho derecho no puede reconocerse desde la fórmula "sufragio voluntario" del artículo 15 de

${ }^{37}$ Según Fernando Atria, en una entrevista para Ciper (10 de noviembre de 2010, bajo el link http:// ciperchile.cl/2010/11/10/abogado-fernando-atria-\%E2\%80\% Cel-voto-voluntario-protege-al-que-no-quierevotar-por-lata $\% \mathrm{E} 2 \% 80 \% 9 \mathrm{D} /$ [consultado el 21 de noviembre de 2012]), que "[v]otar es voluntario, pero la ley puede disponer, por ejemplo, que el que no quiere votar debe declarar su voluntad de no hacerlo en los 30 días previos a la elección, en una comisaría, de modo que habiéndolo hecho no tiene castigo por no votar. (...) $[\mathrm{N}]$ o cualquier manera de no votar es válida”.

${ }^{38}$ Ello justifica el numeral 5 del artículo 132 de la ley de votaciones populares y escrutinios, que prohíbe "hacer cualquier marca o señal en una cédula para procurar violar el secreto del sufragio...".

39 Véanse los numerales 1 y 2 del artículo 136 de la ley de votaciones populares y escrutinios. 
la Constitución. La exposición resultaría incompleta, sin embargo, si no se propusiera una interpretación alternativa del artículo 15 que se enfrente de mejor forma a los desafíos enumerados.

La interpretación que se defenderá puede ser formulada en una única tesis, sin perjuicio de que su manifestación legal discurre en al menos tres direcciones. Sufragio voluntario en el artículo 15 significa que el sufragio debe ser configurado legalmente en términos tales que la acción de sufragar admita ser descrita como una acción voluntaria ${ }^{40}$. Un acción voluntaria, para estos efectos, es aquella que no adolece de defectos deliberativos graves (supra, II, 1.1).

Esto significa que la legislación electoral debe permitir al ciudadano: (i) formarse autónomamente la intención de sufragio y (ii) que el sufragio sea contabilizado según y solo según lo manifestado por el elector. Pues no podría describirse al sufragio como una acción voluntaria si el ciudadano (frente a $i$ ) estuviere imposibilitado de formarse la intención de sufragar, se le induciere a error en este proceso o se le presionare indebidamente $^{41}$. Ni tampoco podría describirse al sufragio como una acción voluntaria, cuando (frente a ii) el valor que se asigna al sufragio fuere distinto al manifestado por el ciudadano al momento de sufragar. Observando cómo se concretan estos aspectos, se tendrá una imagen más clara de las manifestaciónes del sufragio voluntario. Se discutirán tres posibles formas en que esta interpretación se concretaría en el plano legal.

\section{La voluntad de sufragar}

En la discusión acerca del tenor literal de la palabra "voluntario" (supra, II, 2.1) se afirmó que podría considerarse como acción voluntaria aquella acción no motivada por algún defecto deliberativo. En este preciso sentido, la primera concreción de "voluntario" del artículo 15 consiste en permitir que la formación de la intención de sufragio se realice de forma no defectuosa. En otros términos, lo que pretende la configuración del sufragio voluntario es evitar errores e influencias indebidas en la decisión del elector. Ello es institucionalizado típicamente mediante reglas de propaganda electoral. En este sentido, el nuevo artículo 15 de la constitución brindaría apoyo supralegal a la generalidad del párrafo $6^{\circ}$ del título I de la ley de votaciones populares y escrutinios ${ }^{42}$. También responderían a "sufragio voluntario" los artículos 59 y 61 respecto de la propaganda que induce a votar por determinado candidato ${ }^{43}$.

\footnotetext{
${ }^{40}$ Esta no constituye tautología ni definición circular, pues "voluntario", en el definiens se refiere al carácter institucional del voto, mientras que en el definiendum se refiere a una acción, la de sufragar.

${ }^{41}$ Esta protección no es sustancialmente diferente a la dispensada por los artículos 1451 y ss. del Código Civil respecto de los vicios de que puede adolecer el consentimiento.

42 Particularmente los artículos 30 inc. $1^{\circ}, 30$ inc. $4^{\circ}$ y 31.

${ }^{43}$ En virtud del artículo 49 se debe retirar "cualquier efecto de propaganda política o electoral que se encontrare en la cámara" de votación; en virtud del artículo 51 "el voto solo será emitido por cada elector en un acto secreto y sin presión alguna" (énfasis añadido).
} 
El carácter voluntario del sufragio defendido acá brindaría también apoyo constitucional expreso a los numerales 8 y 9 del artículo 136 de la ley de votaciones populares y escrutinios. En el segundo caso ello es evidente cuando la disposición castiga a quien sea sorprendido "presionando a un elector" con discapacidad. El primer caso es, sin embargo, más problemático. De acuerdo con el carácter voluntario del sufragio podría interpretarse de forma extensiva el concepto de "amenaza", incluyendo dentro de ella no solo los casos en que se afecte la posibilidad fáctica de sufragar, sino también aquellos casos en que se influencie indebidamente la voluntad de asisitir a sufragar, aun cuando el elector mantenga cierto grado de control sobre su sufragio. Esta conclusión, aunque susceptible de defensa, requiere de una argumentación coherente con lo establecido en los artículos 296 y 297 del Código Penal.

\section{El valor del sufragio y el Tribunal Constitucional}

La segunda manifestación del carácter voluntario del sufragio subyace a la regulación de la forma y modo en que las preferencias son redactadas, marcadas y contadas. Sufragio voluntario, en este sentido, significa que las preferencias deben ser valoradas según (y solo según) lo expresado en la papeleta. A esto responden las disposiciones 25 a 29 de la ley de votaciones populares y escrutinios ${ }^{44}$, y fundamentalmente la regulación de los artículos 71 inc. $5^{\circ}$ y 73 de la misma ley.

Esta segunda manifestación del sufragio voluntario es coherente con lo afirmado en algunos considerandos del control preventivo -rol 2152-11-CPR-sobre el proyecto de ley de inscripción automática, Servicio Electoral y sistema de votaciones, efectuado por el Tribunal Constitucional el 19 de enero de 2012.

\subsection{El problema}

La disposición sobre la que versan ambas prevenciones es la correspondiente al inc. $2^{\circ}$ del artículo 60 de la ley de votaciones populares y escrutinios. Ella presentaría prima facie un caso de colisión con el carácter voluntario del sufragio, si se interpretase como otorgando un derecho a la abstención. En la parte resolutiva del fallo se resolvió su conformidad a la Constitución sin expresión de fundamento, mas en los considerandos que se comentarán se razonó con mayor profundidad al respecto.

\footnotetext{
${ }^{44}$ Principalmente el artículo 27 inc. $2^{\circ}$ cuando afirma que los errores en la impresión de la cédula no anularán el voto salvo que "sean de tal entidad que hayan podido confundir al elector o influir en el resultado de la elección”; y el art. 29 que consagra la obligación de publicar los facsímiles de las cédulas con las cuales se sufragará. Este último artículo también puede entenderse como protegiendo al elector de posibles errores en su manifestación de voluntad.
} 
La disposición del artículo 60 inc. $2^{\circ}$ establece que:

El elector que concurra a votar deberá hacerlo para todas las elecciones o plebiscitos que se realicen en el mismo acto electoral ${ }^{45}$.

El fundamento sustantivo de esta disposición es expresado con claridad en la prevención de los ministros Carmona y García:

Si los sistemas democráticos tienen por objeto producir mayores o menores grados de representatividad o gobernabilidad, no se puede entender el voto como un dato disociado del efecto general en un sistema electoral democrático.

Habría entonces razones de fondo y de texto para considerar que quien sufraga para una elección presidencial está obligado a sufragar en la elección parlamentaria que compone el acto electoral; de la misma forma que quien sufraga en la elección alcaldicia está obligado a sufragar en la elección de concejales pertinente. Esto significa, en términos prácticos, que se está obligado a depositar la papeleta correspondiente para todas las elecciones que componen el acto electoral, cuando se ha depositado al menos una. ¿Qué consecuencias pueden obtenerse de esta regulación?

\section{2. ¿Proporcionalidad en la afectación?}

Tanto en la prevención de los ministros Carmona y García como en la del ministro Navarro se defiende la constitucionalidad de la norma del artículo 60 inc. $2^{\circ}$. En aquella asoman dos argumentos. El primero asume que la norma sería en principio contraria al carácter voluntario del sufragio, pero que dicha contradicción estaría justificada por razones adicionales de justicia política. Afirman los ministros Carmona y García que el fin constitucional de esta lesión menor de la libertad negativa parcial de un elector se justifica por la certidumbre que genera la fe pública en un acto electoral democrático.

Habría entonces una lesión menor al carácter voluntario del sufragio, justificada por la fe pública en la congruencia del acto electoral democrático. Los ministros deducen esta afectación a la "libertad negativa parcial" del elector desde el sentido que atribuyen al sufragio voluntario del artículo 15 :

El carácter voluntario del voto significa dos cosas. Por una parte, que nadie que esté en condiciones de votar pueda ser forzado a hacerlo. Por la otra, que al no concurrir a votar, no puede recibir sanción alguna.

Afirman los ministros en este pasaje que el artículo 15 otorgaría un derecho constitucional a la abstención que impediría tanto una obligación legal de sufragar como una sanción legal en caso de no asistir a sufragar. A base de lo argumentado (supra II), una posición semejante enfrentaría varios problemas interpretativos de cuya solución rastro

${ }^{45}$ Por "acto electoral" debe entenderse el proceso regulado en el título II de la ley de votaciones populares y escrutinios. En este entendido, es un mismo acto electoral la elección de presidente y parlamentarios a la que se refiere el artículo 26 de la Constitución, como asimismo la elección de alcaldes y concejales a que se refiere el artículo 57 de la ley orgánica constitucional de municipalidades. 
alguno puede encontrarse en el control preventivo. El principal problema, sin embargo, no es la falta de argumentos, sino lo innecesario que resulta la propia interpretación del artículo 15. Pues los ministros parecieran interpretar dicho artículo con el fin de encontrar una colisión con el artículo 60 inc. $2^{\circ}$, para después resolverla bajo un criterio de proporcionalidad en la afectación. Ello es un procedimiento innecesario y poco caritativo con la sistemática legislativa: la prevención se apresura en reconocer una colisión antes de buscar una interpretación que signifique que no hay contradicción alguna. Adicionalmente, si se asumiera el sentido de voluntario sostenido por los ministros, la colisión con el artículo 60 inc. $2^{\circ}$ de la ley de votaciones populares no podría resolverse según un criterio de proporcionalidad, sino solo a base de un criterio de jerarquía: si la prevención fuera consecuente, entonces debiera declararse inconstitucional el art. 60 inc. $2^{\circ 46}$.

\subsection{Al margen de la voluntariedad}

En la prevención de los ministros Carmona y García habría un segundo argumento para considerar que el artículo 60 inc. $2^{\circ}$ no es inconstitucional. Afirman:

$\mathrm{El}$ acto electoral es un asunto que la Constitución le [sic] encarga regular al legislador. Por lo mismo, este puede establecer que el acto electoral comprenda más de una elección. (...) Dicho diseño está al margen de la voluntariedad. La persona puede decidir votar o no. Pero si decide hacerlo, debe sujetarse a las regulaciones que se establezcan ${ }^{47}$.

Lo sostenido en el considerando es correcto, pero su presentación es ambigua. La afirmación de que la regulación del acto electoral está "al margen” del carácter voluntario del sufragio es en principio incorrecta: el diseño del acto electoral es por cierto competencia legislativa, pero ella se ejerce sobre los márgenes que la Constitución establece. La frase parece querer decir, en realidad, que el carácter voluntario del sufragio es independiente de la legislación sobre el acto electoral. Son, por así decirlo, instituciones indiferentes la una de la otra. Sin embargo, esto también sería incorrecto si se considerase al acto electoral parte integrante de la institución del sufragio, pues entonces la regulación del acto electoral también tendría que respetar las características constitucionales de este. En la medida en que no las respete, la regulación legal sería inconstitucional.

Lo que el argumento parece afirmar es que la regulación del acto electoral no sería una especificación del sufragio calificado como voluntario. Es decir, el artículo 60 inc. $2^{\circ}$ no sería lex specialis respecto del sufragio voluntario del artículo 15 de la Constitución. Ello es enteramente correcto desde la interpretación sostenida en este trabajo. Para que los ministros también pudieran tener su propio argumento por correcto, sería necesario que abandonaran su interpretación del sufragio voluntario (supra III, 2.1). Pues los ministros sostienen que el carácter voluntario del sufragio permite que quien desee abstenerse

${ }^{46}$ El juicio de proporcionalidad vendría al caso solo cuando el artículo 60 inc. $2^{\circ}$ de la ley de votaciones populares y escrutinios se considerara lex specialis respecto de otro derecho constitucional. Aquí la proporcionalidad sería un criterio de resolución entre ambos derechos constitucionales. Esto es difícil de sostenerse, y no puede tampoco reconocerse en el fallo.

${ }^{47}$ Punto $9^{\circ}$ de la prevención, folio 409. Énfasis añadido. 
pueda hacerlo, mientras que el artículo 60 inc. $2^{\circ}$ obliga a sufragar a quien eventualmente desea no hacerlo. ¿Cómo la regulación legal entonces estaría “al margen” de la voluntariedad del sufragio?

Así, el problema del argumento de los ministros es su compromiso excesivo con su propia interpretación del artículo 15 de la Constitución. Pues debido a que el artículo 15 consagraría un derecho a la abstención, es el artículo 60 inc. $2^{\circ}$ problemático. Sería, de hecho, una afectación al carácter voluntario del sufragio, aunque (de acuerdo con su tesis) no suficientemente intensa. Desde el punto de vista hermenéutico, debería preferirse en cambio una interpretación del artículo 15 que reconozca el mayor grado de compatibilidad entre las dos disposiciones. Solo así se reduciría la significación del artículo 15 en tanto norma de competencia negativa frente al legislador. Allí radica precisamente la corrección de lo afirmado por los ministros: en su pretensión de dejar al legislador el mayor grado de libertad compatible con la Constitución. El problema es que no alcanzan a apreciar que su definición de sufragio voluntario es una traba injustificada frente a este propósito. La interpretación que este trabajo (a grandes rasgos) construye sería una alternativa viable y menos limitante frente a la legislación que la sostenida por los ministros Carmona y García. Esto resulta compatible, también, con la otra prevención que se comentará ${ }^{48}$.

\subsection{Sufragio voluntario y los votos en blanco}

El fundamento del ministro Navarro para considerar constitucional el artículo 60 inc. $2^{\circ}$ de la ley de votaciones populares y escrutinios es que

nada obsta a que el elector concurra voluntariamente a sufragar en la elección presidencial y al mismo tiempo decida abstenerse de dar su voto a algún parlamentario, o viceversa, teniéndose presente que para todos los efectos -como se indica en [el art. 26 de la Constitución Política]- los votos en blanco se consideran como no emitidos, de manera que siempre el voto mantendrá su carácter voluntario.

El ministro Navarro entiende de forma diferente a los ministros Carmona y García el sufragio voluntario. Mientras estos últimos consideran que nadie puede estar obligado

48 Otro argumento de los ministros es que "el acto o proceso electoral, en la definición del artículo 18 de la Constitución, es indivisible” [énfasis añadido]. Es difícil apreciar dónde radica realmente el carácter indivisible del acto: al menos en el artículo 18 de la Constitución no. Para sostener este argumento, en cambio, lo que debería demostrarse es que el propio concepto de "sufragio", en el artículo 15 de la Constitución incluye esta indivisibilidad, lo que implicaría que el acto de sufragar se verificaría si, y solo si, se votara para todas las elecciones que componen un mismo acto electoral. Así, quien no votare en una de las elecciones que componen el acto electoral, no sufragaría en lo absoluto. Esta tesis reclama una reconstrucción del sistema completo de elecciones populares y escrutinios, lo que excede los márgenes de esta exposición. Sin embargo, para que la tesis fuera correcta, tendría que equipararse los conceptos de "sufragio" y "acto electoral". Ello sería, en principio, aventurado. Además, de dicha equiparación resultaría la inutilidad del artículo 60 inc. $2^{\circ}$, pues si el sufragio fuera, por propia definición constitucional, indivisible ¿para qué reforzar esta indivisibilidad mediante una declaración legal? 
a sufragar ni a recibir sanción por no asistir a hacerlo, el ministro Navarro considera que nadie puede estar obligado a "emitir un sufragio" 49 .

En función del artículo 26 de la Constitución y de los artículos 109 y 172 de la ley de votaciones populares y escrutinios, son votos no emitidos los votos blancos y nulos. Son votos blancos y nulos, de acuerdo con los artículos 71 inc. $5^{\circ}$ y 73 de la ley, aquellos en los que no se marcó preferencia o aquellos en que no puede reconocerse inequívocamente una. Luego, el carácter voluntario del sufragio se vería afectado si los votos que no marcan preferencia se contabilizaran como emitidos, i.e., como marcando preferencia. Esto es lo que impediría, de acuerdo con el ministro Navarro, que la voluntariedad del sufragio se viera afectada: que el elector pueda anular o dejar en blanco su voto; no siendo contabilizados, con ello, como preferencia a favor de algún candidato o candidata. Mientras la regulación no obligue a emitir una preferencia, entonces no se plantea problema constitucional alguno respecto del sufragio voluntario. Esto quiere decir que es absolutamente compatible con el carácter voluntario del sufragio el que se obligue a los electores a depositar la papeleta, como hace el artículo 60 inc. $2^{\circ}$ de la ley de votaciones populares y escrutinios. A lo que no puede obligarse es a marcar determinada preferencia, alguna, o ninguna.

\section{Excurso: El "cohecho al revés"}

Se entiende por "cohecho al revés" la influencia ejercida sobre un ciudadano no con el objeto de que marque determinada preferencia, sino para que se abstenga de marcar alguna cualquiera ${ }^{50}$. El cohecho al revés se prevenía con anterioridad a la reforma con la propia obligación de sufragio, pues al estar el ciudadano obligado a asistir al local de votación a depositar su sufragio, la presión o influencia para obtener su abstención no podía fructificar sin asumirse, al menos, el costo representado por la multa establecida en el antiguo artículo 139 de la ley de votaciones populares y escrutinios. Ahora, al estar derogada la obligación de sufragar, la inadmisibilidad de un cohecho al revés es altamente cuestionable.

Tres disposiciones presentan particular interés frente al cohecho al revés: (i) El artículo 137 de la ley de votaciones populares y escrutinios; ${ }^{51}$ (ii) la palabra "exigir" del

${ }^{49}$ Coincidente con lo afirmado por Chuaqui, p. 196. Véase supra, II (2).

${ }^{50}$ La denominación "cohecho al revés” corresponde a Barros en la comisión Ortuzar. Véase el acta de la sesión $\mathrm{N}^{\circ} 73$ del 26 de septiembre de 1974.

${ }^{51}$ Artículo 137 inc. $1^{\circ}$ : "El que solicitare votos por paga, dádiva o promesa de dinero u otra recompensa o cohechare en cualquier forma a un elector, sufrirá la pena de presidio menor en su grado mínimo a medio". ¿Incurre en este ilícito quien ofreciere un pago o dádiva para que otro se abstenga de asistir a sufragar? Si el sufragio voluntario protegiere la formación de la voluntad del elector, entonces podría considerarse la frase "cohechare de cualquier forma" como castigando también el ofrecimiento de alguna dádiva o recompensa con el fin de generar la abstención. Ello radicaría en que existe una influencia indebida en la decisión de votar protegida por el artículo 15 de la Constitución. Ello debiera ser compatible, sin embargo, con la prohibición de interpretación extensiva de los tipos penales. 
artículo 155 de la misma ley ${ }^{52}$; y (iii) el artículo 169, que establece que el día que se fije para las elecciones y plebiscitos será feriado legal ${ }^{53}$. Podría afirmarse que lo sostenido en este trabajo contribuye a la protección de la formación de la voluntad del elector frente al riesgo de cohecho al revés. Ello es materia de especulación mientras no se desarrolle una reconstrucción general del sistema de votaciones populares y escrutinios, lo que excede los límites de la exposición. En este punto, sin embargo, es necesario observar que el cohecho al revés no representaría problema alguno en caso en que se reconociera un derecho subjetivo a la abstención en la Constitución. Pues si tal derecho constitucional existiera, el cohecho al revés no sería más que el pago para el ejercicio de un derecho constitucional. Si sufragio voluntario significare que el elector puede ausentarse cuando y como guste de la elección, entonces cualquier pago que reciba para fomentar su decisión sería, en principio, válido. Esto vale como reducción al absurdo: quien quiera reconocer en la Constitución un derecho a la abstención, tendría que asumir la carga de contrarrestar esta inequitativa consecuencia.

\section{CONCLUSIONES}

La modificación conjunta de los artículos 15 y 18 de la Constitución trajo consigo varios problemas interpretativos. Particularmente problemática resulta la interpretación de la palabra voluntario en el nuevo artículo 15. Al respecto habría dos tesis: según la primera, el artículo 15 consagraría un derecho a la abstención en sentido fuerte, i.e., un derecho a favor del elector para abstenerse (al menos) de depositar la papeleta electoral.

52 Art. 155: "Ninguna autoridad o empleador podrá exigir servicio o trabajo alguno que impida votar a los electores". "(Inc. $2^{\circ}$ :) En aquellas actividades que deban necesariamente realizarse el día en que se celebrare una elección o plebiscito, los trabajadores podrán ausentarse durante dos horas, a fin de que puedan sufragar, sin descuento de sus remuneraciones”. ¿Qué significa "exigir"? ¿Qué impediría que empleador y trabajador acordaran alguna remuneración adicional para no ausentarse del trabajo? Si el trabajador lo acepta libremente, entonces aparentemente no se configuraría una exigencia en los términos del artículo 155. Esta, desde luego, es una consecuencia plausible pero absurda para un sistema de votaciones que pretende ser equitativo.

Si el artículo 15 de la Constitución, en cambio, se interpretara según lo dicho en este trabajo, entonces sería plausible considerar como hipótesis prohibida dentro del artículo 155 el que empleador y trabajador acuerden condiciones extraordinarias que traigan como consecuencia no asistir a la votación. Pues si "exigir" se interpreta en coherencia con la protección a la formación libre de la voluntad que protege el artículo 15 de la Constitución, entonces una remuneración adicional podría configurar una presión prohibida frente al sufragio voluntario. Esta afirmación, sin embargo, es mera especulación si no se atiende lo dispuesto por el Código del Trabajo.

${ }^{53}$ Con esto satisface el Estado la idea de que quien desee votar pueda hacerlo sin sufrir costos impeditivos. Aún así, con la derogación de la obligación de sufragar empeoró la posición relativa de quienes desempeñan trabajos libres e informales el día de la votación. Estas personas, presumiblemente de escasos recursos materiales, preferirán trabajar el día de la elección en vez de asistir al local de votación. La derogación de la obligación de votar, como es evidente, lleva la desigualdad de ingresos al plano de las elecciones. Esto ya había sido advertido por la literatura (por todos, Lipjhart, A., "Unequal participation: Democracy's unresolved dilemma, en American Political Sciencie Review 91 (1), 1997, passim), pero aún así fue ignorado por la modificación constitucional. Ninguna modificación legal hasta la fecha se ha hecho cargo de este problema, aunque se ha propuesto ya en la discusión pública que el transporte público sea gratuito el día de la elección. Ello sería acorde con la protección del sufragio "voluntario". 
De acuerdo con lo sostenido, en cambio, un derecho semejante no puede reconocerse en la Constitución. La palabra voluntario del artículo 15 no implica un derecho a la abstención (II, 1.1), la intención legislativa al momento de su promulgación no es razón suficiente (II, 1.2), la historia fidedigna aboga por una amplia zona de competencia legislativa (II, 1.3), y la sistemática constitucional no permite deducir este derecho ciudadano directamente a partir del artículo 15 (II, 1.4).

En este trabajo se asigna al adjetivo voluntario del artículo 15 un sentido diferente. El artículo 15 obliga al legislador a regular el sufragio de forma que su ejercicio admita ser descrito como una acción voluntaria. Las consecuencias que esta formulación traería aparejada son: (i) evitar presiones indebidas al momento de sufragar; (ii) determinar la forma en que las preferencias deben entenderse marcadas y contadas; y (iii) otorgar protección (acaso suficiente) frente al cohecho inverso. Los tres objetivos están plenamente interrelacionados, aunque aquí se hayan presentado de forma separada. Por cierto, otras formas de concretización del sufragio voluntario podrían reconocerse dentro de la legislación. Por ejemplo, el sufragio voluntario podría tener rendimiento frente a la regulación del gasto electoral, al comportamiento electoral de los funcionarios de gobierno o frente a la prevención del clientelismo. Lo importante radica en advertir que ninguna de estas formas de concretización depende del reconocimiento de un supuesto derecho a la abstención del elector.

A la luz de lo dicho hasta acá, es posible responder un conjunto de preguntas a modo de conclusión:

(1) ¿Puede el ciudadano con derecho a sufragio abstenerse de sufragar hoy en Chile? La respuesta presumiblemente debiera ser afirmativa. Pero en contra de lo que suele pensarse, abstenerse sería posible hoy en Chile básicamente porque fue derogada la obligación constitucional (del antiguo artículo 15) y la sanción del artículo 139 de la ley de votaciones populares y escrutinios. Con ello, la abstención en el sistema jurídico chileno es irrelevante: a la Constitución no le interesa si el ciudadano sufraga o no. Es un error pensar, en cambio, que es posible abstenerse hoy en Chile porque existe un derecho constitucional que admite la abstención. La pregunta sobre si el ciudadano debe sufragar o si puede abstenerse no obtiene respuesta alguna por parte de la Constitución.

(2) ¿Puede el legislador restablecer la obligación de sufragar? Naturalmente. Cualquiera nueva disposición que el legislador decida promulgar en orden a obligar a los ciudadanos a sufragar es en principio compatible con el carácter voluntario del sufragio, y por ende, plenamente constitucional. Esto quiere decir que el legislador es libre de determinar cualquier incentivo, incluyendo sanciones por inasistencia del ciudadano al local de votación, pues al menos el artículo 15 de la Constitución no plantea límite alguno al respecto ${ }^{54}$. Es cuestionable, incluso, si para establecer

${ }^{54}$ El asesor electoral de la Secretaría General de la Presidencia, Andrés Tagle, declaró para Emol el 3 de noviembre de 2012 que "la ley de voto voluntario está establecida en la Constitución (!) de la República y modificarla no es un trámite fácil. Tuvo una amplia mayoría en el Congreso y (...) se necesitan tres quintos 
dichos incentivos se requiere el cuórum correspondiente a una ley orgánica constitucional. Ello dependerá de qué tan extensiva o restrictiva sea la interpretación del artículo 18 inc. $1^{\circ}$ de la Constitución.

(4) ¿Puede el legislador establecer incentivos para votar? Sí: la multa puede considerarse un incentivo. Pero en general todo otro premio, apremio, gratificación o incentivo que se otorgue a quien participa electoralmente es constitucionalmente admisible. Al no existir un derecho a la abstención electoral, los incentivos que el legislador establezca para no abstenerse (v.gr. una mejor posición relativa al momento de optar a cargos públicos, una exención o una rebaja tributaria, etc.) no generan en principio una afectación al sufragio voluntario.

(5) ¿Puede el legislador desincentivar la participación electoral? Ello es problemático. En principio la respuesta debiera ser negativa, en tanto desde una consideración refinada de los artículos 13 y 15 de la Constitución resulta protegida la voluntad de sufragar. El legislador contaría, así, con mucho más margen para incentivar la participación electoral que para desincentivarla, en tanto el desincentivo podría significar una afectación al carácter voluntario del sufragio como al propio derecho a sufragio, en caso de ser uno prohibitivo. Debido al precario estado actual de la regulación constitucional, no puede sino especularse a este respecto.

Estas respuestas hablan en contra de considerar superada la discusión sobre el sistema de votaciones populares y escrutinios. Este trabajo se ha restringido a presentar una argumentación jurídica (no de justicia política ni de racionalidad de fines) con el fin de advertir que la Constitución, frente a la abstención, se mantiene en silencio: tanto ella como sus consecuencias negativas esperan una respuesta legal, no constitucional. En principio es una buena noticia el que una Constitución calle: su silencio significa un impulso a la decisión mayoritaria, democrática y representativa encarnada (idealmente) en el proceso legislativo. Para un legislador que no sabe cómo responder al silencio, la libertad que la Constitución otorga puede significar una incómoda carga. Cómo se reaccione frente a los desafíos que la Constitución plantea es, desde el punto de vista jurídico, todavía materia de discusión política y electoral.

\section{BIBLIOGRAFÍA}

Alchourron, Carlos y Bulygin, Eugenio, Normative sistems. Springer, Nueva York, 1971.

Austin, J.L.: "A plea for excuses”, en, del mismo: Philosophical Papers (segunda edición). Oxford University Press, Oxford, 1970.

BöCKENFÖRDE, Ernst- Wolfgang, "Die Methoden der Verfassungsinterpretation - Bestandaufnahme und Kritik”, en, del mismo: Wissenschaft, Politik, Verfassungsgericht, Suhkamp, Berlin, 2011,

de la votación [sic] [para modificarla]" (énfasis añadido). Esta afirmación es incorrecta. Pues si fuera materia de ley orgánica constitucional, la incorporación de la obligación de sufragar requiere de las 4/7 partes de los diputados y senadores en ejercicio; si no lo fuera requeriría solo la mayoría simple. 
Chauqui, Tomás, "Participación electoral obligatoria: una defensa”, en Modernización del régimen electoral chileno. PNDU, Santiago, 2007.

Davison, Donald, "Freedom to act. (1973)", en, del mismo, Essays on actions and events, Clarendon Press, Oxford, 1980.

FaCkeldey, H.G., Norm und Begründung. Zur Logik normative Argumentierens, Peter Lang, Berna, 1992.

Frankfurt, Harry, The importance of what we care about, Cambridge University Press, Nueva York, 1998.

Heun, Werner, Originalism als Interpretationsmethode im US.-amerikanischen Verfassungsrecht", en Verfassunsänderung, Verfassungswandel, Verfassungsinterpretation (Ed. Rainer Wahl), Duncker \& Humblot, Berlin, 2008.

HoHFELD, W.N., Fundamental legal conceptions as applied in judicial reasoning and other legal essays, Yale University Press, New Heaven, 1919.

ItURRALDe, Victoria, "Consideración crítica del principio de permisión según el cual 'lo no prohibido está permitido'”, en Anuario de Filosofía del Derecho 15, 1998.

Lipjhart, A., "Unequal participation: Democracy's unresolved dilemma, en American Political Sciencie Review 91 (1), 1997.

Marshall, Pablo, "El derecho y la obligación de votar", en Revista de Derecho XXII (1), 2009.

SIERRA, Lucas, "El voto como derecho: una cuestión de principios", en Modernización del régimen electoral chileno, PNDU, Santiago, 2007.

SAVINGY, Friedrich Carl von, "System des heutigen Römischen Rechts", Verlt und Comp., Berlin, 1840.

Wright, G.H. von, “Deontic Logic”, en Mind, Vol. 60 (237), 1951.

Wright, G.H. von, Norm and Action. A logical enquiry, Routledge und Kegan Paul, Londres, 1963.

Vendler, Zeno, “Agency and Causation”, en Midwest Studies in Philosophy IX, 1984.

Williams, Bernard, "How free does the will need to be?” en, del mismo, Making sense of Humanity, Cambridge University Press, Cambridge, 1995.

ZúÑIga Urbina, Patricio, "Derecho de sufragio y obligatoriedad", en Hemiciclo. Revista de Estudios Parlamentarios 1 (1), 2009. 